\title{
COURSEWORK IN AUSTRALIAN PHD PROGRAMMES
}

\author{
WHY IS THIS A BOUNDARY AND \\ HOW IS IT BEING PUSHED?
}

Margaret Kiley, Joe Luca and Anna Cowan

\section{BACKGROUND}

Other than in a few isolated instances, the Australian PhD has been almost exclusively through 'experiential research learning'. In other words candidates work with a supervisor or supervisory panel who guides their learning of, and about, research through undertaking a research project. To support candidates and supervisors universities generally offer a broad range of workshops, seminars, and other learning activities (Cumming \& Kiley 2009) but until very recently, formal coursework has not been a standard part of the Australian PhD although it is part of the Professional Doctorate.

Within this context, it is of note that over the past 12 to 18 months the introduction of coursework into the Australian $\mathrm{PhD}$ is a development that is quickly gaining interest, although with varying levels of support from candidates and supervisors. One of the major areas of discussion relates to whether the coursework is related to research processes e.g. research methods, or whether it is more of a disciplinary nature, or whether it should be more closely related to employment capability.

This paper reports the findings from a research project currently being undertaken in Australia and includes the various negatives and positives that candidates and staff have expressed regarding the introduction of formal coursework, and the models being developed. It notes the boundaries between coursework and research degrees and the hurdles they present to students, supervisors and institutions.

It is of interest that the development of coursework in the Australian PhD is occurring at the same time as the implementation of the new Australian Qualifications Framework (AQF) and the introduction of the Tertiary Education Quality Standards Agency (TEQSA). These two separate but linked developments have caused all 
universities to examine and more closely define curriculum, course articulation, and pedagogical implications at the postgraduate coursework and research levels. Given that Australia is one of the few countries that does not offer formal coursework in the PhD it is worth looking at those systems that do. For example in North America the doctorate involves a combination of research and coursework with increasing specialisation and intensity. The provision of coursework in $\mathrm{PhD}$ programmes is commonplace in North America and Europe and it is of interest to note that when a phrase such as 'coursework in the PhD' is mentioned in Australia the most common response is 'Oh, you are talking about the US model'. Certainly the doctoral degree in North America involves a combination of research and coursework. Furthermore, the doctorate across Europe includes coursework and in the UK it is noteworthy that the inclusion of coursework in the doctorate is becoming increasingly common (see for example http://www.esrc.ac.uk). Having said that, in Australia the professional doctorate has included coursework, however, despite a surge in popularity in the 1990s, the number of professional doctorate programmes in Australia accounts for a very small percentage of the total doctoral enrolment.

Therefore, while we can learn from other systems and models, the adoption of programmes from elsewhere is clearly not appropriate given the particular qualities of the Australian PhD programme. One of these qualities is the funding model in Australia which leads some Australian Deans to consider the addition of coursework to be out of the question. One of the main reasons for this view is that funding for $\mathrm{PhD}$ candidates through the Research Training Scheme (RTS) is for a maximum of 4 years (FTE) and there is some concern that coursework will increase the time to completion. Given that Government funding is only for the four years of funding provided by the RTS, it is not surprising that many university Deans of Graduate Research are concerned that if there is additional time required for coursework then from where will the funding come? Additionally, where do universities find the funding to cover the costs of additional coursework teaching? These are just some of the issues related to the possible introduction of coursework in the PhD. Despite these issues, an informal survey of Australian universities conducted early in 2013 found that 55 per cent reported that they have been actively discussing and implementing some form of doctoral coursework into their $\mathrm{PhD}$ and another $20 \%$ considering this action in the near future.

In curriculum terms, a basic question that needs to be answered is: Should coursework in the doctorate be provided to address a perceived deficit in the candidate's prior research learning, or is coursework a means of 'value-adding' to a learning experience. Or maybe coursework should relate to broader skills 
such as leadership. For example, McAlpine and Asghar (2010) suggest institutions could offer candidates leadership that incorporates the broad skills of "teamwork, communication and collaboration". An issue impacting on this question relates to the increasing variation in 'the Australian PhD'. While an obvious variation might be claimed to be the Professional Doctorate and the $\mathrm{PhD}$, recent research suggests that there is substantial variation within the programme generally termed 'the PhD' (Group of Eight 2013) as well as the pathways into a doctoral programme (Kiley 2011 ). With an average commencing age of 33 for $\mathrm{PhD}$ candidates across all disciplines (Department of Innovation 2011) it is clear that many candidates have had substantial work experience prior to commencing their doctoral studies, particularly in the social sciences. Furthermore, the percentage of international students undertaking doctoral studies has increased considerably for example "total research student numbers from 2001 to 2010 increased by 29\%, principally due to overseas student growth with the proportion of domestic students decreasing from 86 per cent to 73 per cent" (Larkins 2012:2).

Workforce issues are significant issues in Australia and the employability of doctoral graduates has come under considerable scrutiny (Neumann \& Tan 2011 ; Department of Industry 2012). However, this discussion is not confined to Australia. For example, Kyvik and Olsen (2012) undertook a study in Norway which addressed graduates' views on the relevance of doctoral coursework to three types of employment, academia, applied research institutes and industrial laboratories, and non-research workplaces. They found that while the coursework was considered less helpful than the knowledge they had gained from their research, for those working in non-research environments, the various generic skills they had developed were considered more helpful than in other employment areas.

A further issue related to coursework relates to pedagogy, that is, how are the various learning experiences provided for candidates? From studies undertaken by Cumming and Kiley (2009) and McAlpine and Asghar (2010:168) to name just two, many of the positive experiences reported by candidates were of a collaborative, candidate-centred nature. These include experience such a reading and writing groups, involvement in professional associations, and work experience.

This chapter addresses some of these above issues through a study undertaken with two Australian universities. The study reported here was part of a larger study undertaken across a range of Australian universities but these two universities undertook specific, in-depth studies with a view to introducing some form of coursework into their existing programmes. 


\section{RESEARCH DESIGN}

The two universities involved in the study were quite different from one another. University $A$ is a new generation university with a strong focus on the professions and, on the whole, a mature-age student cohort. This university has a very active Graduate Centre that initiates policy development and its implementation across the institution as well as support and development for all candidates and supervisors. This institution had discussed the idea of introducing coursework, but this had not been formalised at the time of the research. For University A, supervisors and candidates across a range of Humanities and Social Sciences (HASS) and Science, Technology, Engineering and Mathematics (STEM) disciplines were involved in the research. University B, on the other hand, is a research-intensive university and only the Science supervisors and candidates were involved. The focus on Sciences was for a number of reasons, with one of the main ones being that the Social Sciences at that university had already introduced coursework and the study was aimed at working with groups considering the introduction of coursework. This university has a decentralised approach to policy development and implementation. This is evidenced by different parts of the university having quite different policies and practices related to coursework in the PhD. For example, one faculty has had required $\mathrm{PhD}$ coursework for almost 30 years, another had introduced quite different forms of coursework a few years ago, and some faculties have no requirements regarding coursework at all. The faculty in the study was at the stage of considering the introduction of coursework.

Given the structures and approaches of these two institutions, and that they were in quite different parts of the country and representing quite different types of institutions, they were regarded as excellent choices to demonstrate variation as well as any possible similarity in the research.

Data were collected from both universities using two different methods. The first was from workshops and focus groups with staff and candidates. The second was from an online survey to candidates.

The aim of the workshops and focus groups was to facilitate participants in their discussions of the various issues related to why they might want to introduce coursework, how they might do that and what the content might address. Overall, 70 candidates and supervisors took part in the workshops/focus groups (31 at University A and 39 at University B). The second form of data came from an online survey administered to candidates from each of the universities. The survey asked candidates about their views and experiences of coursework, their expectations of employment after their doctorate; and various kinds of demographic information 
related to study and employment. Responses to the survey varied with 132 from University A and 185 participating from University B (response rates of 19 per cent and 23 per cent respectively).

\section{FINDINGS}

\section{Focus groups of supervisors and candidates}

With each focus/discussion group with staff and candidates the most common responses early in discussion were negative, for example:

- If students were 'off doing coursework' that would take time away from their 'research' requiring additional candidature time but there was no additional funding

- Coursework implied a lack of individual learning and development opportunities if candidates were all required to undertake the same coursework

- When should coursework be offered, should it be at the beginning, at the end or throughout candidature?

- How could the disciplinary nature of research degrees be addressed if there was some form of faculty of university required coursework?

- Who would teach these courses when staff already had full teaching loads and would they have the expertise and who would handle the additional administrative loads?

However, after some discussion several perceived benefits of formal coursework emerged as follows:

- The development of peer networks through being in courses thereby alleviating isolation, particularly in the Humanities and Social Sciences.

- Opportunities for candidates to work across disciplinary and epistemological boundaries.

- Assistance to supervisors in that they did not have to work with each candidate on the same issues, i.e. levels of efficiency.

- The possibility of a more equitable education for candidates with less reliance on the quality of individual supervisors.

- Opportunities to address particular values and directions of the university.

- Greater opportunities to address employability and generic skills.

Given the diversity of candidates which include increases in international enrolments, part-time (almost 50 per cent for domestic candidates have some periods of part-time enrolment), females (now 50 per cent) and age as noted above it is not surprising that an issue that arose strongly in any workshops with research supervisors and candidates was the passion with which those involved addressed the importance of 
recognizing and accommodating the individual needs of candidates, as well as the school and disciplinary idiosyncrasies which shape the candidate's experience. In several cases, in initial discussions, staff can see no way in which candidates could engage in some form of faculty, let alone university-wide programme. Academics and candidates argued that there needed to be greater flexibility, as well as being much more alert to what is needed and how and when it is provided or delivered. Much of this thinking accounts for suggestions such as Individual Learning Plans for candidates. Similarly, it was suggested that many candidates needed to be more proactive in terms of determining their own learning needs and required training and development.

Once some of the major issues had been discussed, the groups began to discuss content, including aims and learning outcomes. From the discussion it was possible to identify three main kinds of courses, namely enabling, enriching and articulating courses:

- Enabling courses aim to assist candidates in 'getting off to a good start' and/or to accommodate candidates who are underprepared in research. These courses might have a focus on research processes which are front-ended into the first six to nine months of candidature or advanced level disciplinary knowledge in the first 12 months. Such courses are often considered as providing exit qualifications e.g. Graduate Certificate or Diploma, for candidates who do not complete the PhD award.

- Enriching or value-adding, the second view, is where a university provides specific experiences for candidates that are beyond the standard 'completion of a PhD'. These experiences might relate to the nature of the university, for example the values of social justice or ensuring that one's research contributes to the region. Or, they might be designed to enable candidates to gain experiences by studying in another country or institution for part of their candidature.

- Articulating, the third view, relates to skill development to meet the perceived criticisms of employers. These courses are generally made available later in candidature or on completion of the degree and might include experiences such as teaching, project and financial management or six-months industrial/commercial setting that provides assessable skill development in an authentic setting beyond the academy.

Decisions as to the type of approach have been motivated by a number of factors including: the size of candidate cohort; the characteristics of the 'typical' candidate: and the characteristics of the discipline and university. 


\section{Survey results from candidate survey}

The survey results are presented in two main parts: a) the demographic differences and b) comments related to coursework with comments related to demographic differences where relevant.

\section{Demographic differences}

The respondents from the two universities were both very similar with regard to the split between domestic (just on 70 per cent) and international (30 per cent) each. Also, the respondents were very similar in their stage of candidature at the time of completing the survey with approximately 28 per cent in the first third of candidature, 26 per cent in the middle 46 per cent in the final third. Table 9.1 outlines some of the demographic details of the respondents including sex, age, enrolment type and employment prior to candidature.

TABLE 9.1 Respondent demographics sex, age, enrolment status, programme and employment

\begin{tabular}{|l|l|l|}
\hline Female & University A \% & University B \% \\
Male & 69 & 61 \\
\hline Age: & 31 & 39 \\
\hline - $20-29$ & 7 & \\
- $30-39$ & 35 & 53 \\
- $40-49$ & 24 & 26 \\
- 50-59 & 29 & 14 \\
- $60+$ & 5 & 5 \\
\hline Full-time & 64 & 2 \\
Part-time & 36 & 80 \\
\hline Enrolled in: & 95 & 20 \\
\hline - PhD & 95 & \\
- Professional Doctorate & 1 & 98 \\
- Other & 55 & 1 \\
\hline Employment prior to candidature: & & 49 \\
- Full-time & 36 & 34 \\
- Part-time/casual & 9 & 17 \\
\hline - Not at all & &
\end{tabular}

The data regarding age accord with recent Australian Government data that suggests that while the median age at commencement of all candidates in Australia across all disciplines is 33, in the Chemical Sciences, for example, the median age is 22 and in areas such as Education it is closer to 45 years (Department of Innovation 2011 ). 
Of all respondents employed prior to enrolment, 49 per cent in University A had been employed in the Education field, followed by 20 per cent in government and in University B 47 per cent had been employed education, followed by government with 21 per cent. Education was also the most popular field for both cohorts with regard to anticipated employment after graduation with remarkable similarity between the two cohorts of 67 per cent from University A and 68 per cent from University B with over 80 per cent from both groups expecting their employment to be in the university sector rather than schools or the technical and vocational education sectors.

\section{Views on coursework}

Following the details regarding the demographic data of respondents, we now move on to respondents' experiences and views on coursework in the PhD. Given that formal coursework had not yet been introduced into the two cohorts, it is not surprising that only quite small percentages of respondents had undertaken coursework as part of their doctoral programme: in University A 15 per cent and University B only 10 per cent had been undertaking formal coursework. With such a small number it is difficult to draw any conclusions from the following, however, as a matter of interest all agreed that the courses were relevant to their doctoral programme and the main benefits of the coursework included:

- Providing background knowledge for doctoral research

- Increasing knowledge about the discipline field

- Helping solve problems in the field of study.

However, when all respondents were asked if they thought coursework should be required 55 per cent and 52 per cent respectively suggested that approximately one third of their doctoral programme should be coursework with the majority suggesting it should be in the first year of candidature.

\section{DISCUSSION}

From the research two specific examples serve to demonstrate the variation of institution, curriculum and purposes for introducing coursework into the PhD.

The first example is from University $A$, the new generation university with a strong focus on the professions. At this university, using the Australian Qualifications Framework (AQF) as a model, staff and candidates started by developing a matrix of learning outcomes that they believed candidates should be able to demonstrate at the completion of their doctoral programme. With this matrix the university is now developing individualised skills audits and learning plans. These will be provided to 
enable candidates to work with their supervisory team to identify the areas in which they have strengths and where there are areas that need addressing. From there each candidate will develop a learning plan to assist them in meeting the university's milestones for candidature. This outcome has been particularly important to staff at that institution because it explicitly addresses the strong focus on the individual candidate and supervisory team that had been made so clear in early discussions.

The second example comes from one discipline in the Sciences at University B. This discipline generally takes younger students, i.e. early or mid-twenties from a variety of undergraduate disciplinary backgrounds, and so staff are very keen to introduce one year of coursework at the beginning of doctoral candidature which is disciplinary in nature. This, they argue will ensure that all PhD candidates are 'on the same page' when they commence their research given the variation in their previous disciplinary experience.

Other examples identified from the broader research project include:

- Four formal research-processes courses in which candidate enrol and must successfully complete in their first 12 months.

- Two courses related to approaches to research and ethics which are conducted across the whole university for all new candidates in their first year. This approach is designed to provide new candidates with a broad overview of the different type of research being undertaken across the institution and the related research methods.

As this chapter has attempted to demonstrate, suggesting something seemingly as

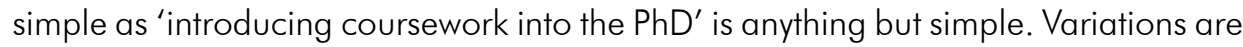
evident depending on university type, candidate cohort, and discipline. As various models emerge, and as staff and candidates become more used to the idea of coursework in the $\mathrm{PhD}$, it is anticipated that institutions will learn and 'borrow' from one another but for the moment the strong variation provides an exciting opportunity for curriculum developments in Australian research education.

\section{ACKNOWLEDGEMENT}

Support for this project has been provided by the Australian Government Office for Learning and Teaching. The views in this project do not necessarily reflect the views of the Australian Government Office for Learning and Teaching.

\section{REFERENCES}

Cumming J. \& Kiley M. 2009. Research Graduate Skills Project. Canberra, Australian National University. 
Blitzer E, Albertyn R, Frick L, Grant B, Kelly F (eds) 2014. Pushing Boundaries in Postgraduate Supervision. Stellenbosch: SUN PRESS

\section{PART FOUR • SUPERVISION STRATEGIES}

Department of Industry, Innovation Science, Research and Tertiary Education. 2012. Australian Small Business: Key statistics and analysis. Canberra: Department of Industry, Innovation Science, Research and Tertiary Education.

Department of Innovation Industry Science and Research. 2011 . Research skills for an innovative future: A research workforce strategy to cover the decade to 2020 and beyond. Canberra: Department of Innovation, Industry, Science and Research (DIISR).

Department of Innovation Industry Science and Research. 2011 . Research workforce strategy: Discipline case studies. Canberra: DIISR.

Group of Eight. 2013. The changing PhD: Discussion paper. Canberra: Group of Eight.

Kiley M. 2011 . Where are out doctoral candidates coming from and why? Canberra: The Australian National University.

Kyvik S. \& Olsen T. 2012. The relevance of doctoral training in different labour markets. Journal of Education and Work 25(2):205-224.

Larkins F. 2012. Australian Higher Education Policy Analysis: Gender, citizenship and discipline in Australian Higher Education Research Training. Melbourne: L.H. Martin Institute.

McAlpine L. \& Asghar A. 2010. Enhancing academic climate: Doctoral students as their own developers. International Journal for Academic Development 15(2):167-178.

Neumann R. \& Tan T. 2011 . From PhD to initial employment: The doctorate in a knowledge economy. Studies in Higher Education 36(5):601-614. 